\begin{tabular}{cc|c}
\hline Tar. Bil. Der. & Journal of Agricultural Sciences \\
& $\begin{array}{c}\text { Dergi web sayfası: } \\
\text { www.agri.ankara.edu.tr/dergi }\end{array}$ & Journal homepage: \\
& www.agri.ankara.edu.tr/journal
\end{tabular}

\title{
Türkiye’nin Doğu Bölgesinden Toplanan Bazı Yerel Ekmeklik Buğday Popülasyonlarından Seçilen Saf Hatların Yüksek Molekül Ağırlıklı Glutenin Alt Birimlerinin İncelenmesi
}

\author{
Ayşe YILDIZ ${ }^{a}$, Kadir AKAN ${ }^{a}$, Mevlüt AKÇURA ${ }^{\text {b }}$ \\ ${ }^{a}$ Tarla Bitkileri Merkez Araştırma Enstitüsü Müdürlüğ̈̈ Şehit Cem Ersever Caddesi, No: 9-11 Yenimahalle, Ankara, TÜRKIYE \\ ${ }^{\boldsymbol{b}}$ Çanakkale Onsekiz Mart Üniversitesi, Ziraat Fakültesi, Tarla Bitkileri Bölümü, Terzioğlu Yerleşkesi, Çanakkale, TÜRKIYYE
}

\section{ESER BILLISII}

Araştırma Makalesi

DOI: 10.1501/Tarimbil_0000001337

Sorumlu Yazar: Ayşe YILDIZ, E-posta: varolyildiz@hotmail.com, Tel: +90 (532) 5089685

Geliş Tarihi: 04 Kasım 2013, Düzeltmelerin Gelişi: 11 Haziran 2014, Kabul:11 Eylül 2014

\section{ÖZET}

Bu araștırmada Türkiye'nin doğu bölgesinden toplanan bazı yerel ekmeklik buğday popülasyonlarından seçilen saf hatlardan tane verimi, verim unsurları ve bazı kalite özelliklerine göre belirlenen 41 adet genotipin, SDS-PAGE yöntemi kullanılarak Glu-1 lokusunda bulunan yüksek molekül ağırlıklı glutenin (YMAG) alt birimleri incelenmiştir. Ekmeklik buğday saf hatlarında Glu-1 lokusuna ait 9 tane allel belirlenmiștir. Glu-A1 lokusuna ait sadece null alleli (c) belirlenirken, Glu-B1 lokusuna ait 7+8 alt birimi (b) 35 (\% 85.4) saf hatta $13+16$ alt birimi (f) 2 (\% 4.9) saf hatta, 7 (a), 14+15 (h), 17+18 (i) ve $6+8$ (d) alt birimleri ise sadece 1'er (\% 2.4) saf hatta gözlenmiştir. Glu-D1 lokusunda a alleli 34 (\% 82.9) saf hatta, d alleli 7 (\% 17.1) saf hatta belirlenmiştir. Yedi farklı YMAG alt birimleri kombinasyonlarının saptandığı çalışmada en yaygın olarak (\% 78.0) gözlenen "n, 7+8 ve 2+12" kombinasyonu 32 saf hatta belirlenmiştir. Sadece 5 saf hat (\% 12.2) 8 kalite skor değerini alırken, 36 (\% 87.8) saf hattın skor değerinin 4-6 arasında değiştiği tespit edilmiştir.

Anahtar Kelimeler: Türkiye yerel ekmeklik buğdayları; SDS-PAGE; Yüksek molekül ağırlıklı glutenin (YMAG)

\section{Analysis of High Molecular Weight Glutenin Subunit Composition of Pure Lines Selected from Eastern Turkey Bread Landraces}

\section{ARTICLE INFO}

Research Article

Corresponding Author: Ayşe YILDIZ, E-mail: varolyildiz@hotmail.com, Tel: +90 (532) 5089685

Received: 04 November 2013, Received in Revised Form: 11 June 2014, Accepted: 11 September 2014

\section{ABSTRACT}

In this research, high molecular weight glutenin (HMWG) subunit composition, found on Glu-1 locus of 41 genotypes selected according to grain yield, yield components and some quality properties from bread wheat landraces collected from Eastern Turkey, has been investigated by using SDS-PAGE method. Of the bread wheat pure lines, nine Glu-1 locus alleles have been determined in genotypes. While only null allele (c) on Glu-A1 locus has been determined, on Glu-B1 
locus $7+8$ subunit (b) in 35 pure lines $(85.4 \%), 13+16$ subunit (f) in 2 pure lines $(4.9 \%)$, subunits 7 (a), $14+15$ (h), $17+18$ (i) and $6+8$ (d) $(2.4 \%)$ have been determined in only one genotype. On Glu-D1 locus allele a in 34 pure lines $(82.9 \%)$ and allele $\mathrm{d}$ in 7 pure lines $(17.1 \%$ ) have been determined. In this research in which 7 different HMWG subunit combination were determined, the most common group found in 32 pure lines $(78.0 \%)$ was n, $7+8$ and $2+12$. Of the genotypes, only 5 pure lines (12.2\%) have taken 8 quality score value whereas the quality score value of 36 pure lines $(87.8 \%)$ has been determined changing between 4 and 6 .

Keywords: Turkish landraces bread wheat; SDS-PAGE; High molecular weight glutenin (HMWG)

(C) Ankara Üniversitesi Ziraat Fakültesi

\section{Giriş}

Serin iklim tahıllarından buğday, ülkemizde olduğu gibi tüm dünyada da insan beslenmesinde oldukça önemli bir yer tutmaktadır. Türkiye'de buğdayın tüm tarım alanlarında üretimi yapılabilmekle birlikte toplam işlenen arazinin \% 51'inde buğday yetiştirilmektedir. 2012 y1lı üretim değerleri göz önüne alındığında Türkiye'de buğday, 7.5 milyon ha alanda ekilmiş ve yaklaşık olarak 20.1 milyon ton üretilmiştir (TÜİK 2013). Ekmeğin ham maddesi olan ve dünyanın 50 ülkesinde birinci derecede besin maddesi olan buğday yaklaşık olarak dünya nüfusunun \% 35'inin temel besin maddesi ihtiyacını tek başına karşılamaktadır. Türkiye'de insan beslenmesinde \% 80-85'i ekmek olmak üzere diğer yan ürünlerle birlikte ortalama kişi başına yıllık 205 $\mathrm{kg}$ buğday tüketilmekte ve günlük enerji ihtiyacının \% 52'si buğdaydan karşılanmaktadır (Keçeli 2008). Bunun yanında buğdayın hayvan beslenmesinde ve farklı endüstri alanlarında geniş kullanım alanlarının olduğu bilinmektedir.

Türkiye, buğdayın ilk kültüre alındığı ve en önemli gen merkezlerinden birisidir. Bu nedenle kalite 1slah çalışmalarında doğrudan veya dolaylı olarak kullanılabilecek, genetik tabanı daralmış olan gen havuzunun geliştirilmesine imkan verebilecek zenginlik ve çeşitlilikte yerel buğdaylara sahiptir. Birçok saf hattın karışımı olabilen yerel çeşitler, ileri kademe sslah materyalleri ve Türkiye veya diğer ülkelerde geliştirilmiş çeşitler arasından seçilen, amaca uygun ve istenilen özellikleri taşıyan genotipler sslah çalışmalarında varyasyon kaynağı olarak da kullanılabilir (Akçura 2006; 2011). Bu özellikleri nedeniyle yerel ekmeklik buğdaylar, buğday ıslahçıları için kalite özelliklerini istenen yönde geliştirebilecek potansiyel gen kaynaklarıdır. Üretimi yapılan ve gen kaynağ 1 olabilecek yerel buğday çeşitlerinin ekim alanları farklı nedenlerle daralmakta hatta üretimden tamamen kaldırılmaktadır. Bunun yanında yerel buğdayların kalite ıslahında gen kaynağı olarak kullanmasına yönelik araştırmalar oldukça sınırlı olup bu konu üzerinde yeteri kadar durulmamıştır. Islah çalışmalarının hızlı ve etkin bir şekilde hedefine ulaşılabilmesi için farklı yerel buğday gen kaynaklarının toplanması, karakterizasyonu, gen kaynağı olarak ıslah programlarında yer alması ve Ulusal Gen Bankalarında korumaya alınması oldukça önemlidir (Akçura 2006). Bu amaçla öncelikli olarak gen havuzundaki varyasyonun genişletilmesi amaciyla yerel buğday çeşitlerinin toplanması ve hedef karakterler bakımından yeterli varyasyonunu gösterip göstermediğinin belirlenmesi şarttır.

Buğday endosperm proteinlerinin büyük bir bölümünü oluşturan gluten proteinleri, buğday ununun visko-elastik özelliklerinden sorumludur. Buğday gluten proteinleri gliadinler ve gluteninlerden oluşmaktadır (Shewry et al 1995). Polimerik gluteninler molekül ağırlıklarına göre yüksek molekül ağırlıklı glutenin (YMAG) ve düşük molekül ağırlıklı glutenin (DMAG) olmak üzere ikiye ayrilır. YMAG proteinleri toplam un proteininin \% 5 'ini oluşturmasına rağmen ekmeklik kalitesini ve hamurun reolojik özelliklerini belirleyen en önemli faktörlerdir (Rogers et al 1989). YMAG alt birimlerinin bulunması veya bulunmaması ile oluşturulan allel kombinasyonları uzun yıllardır ekmek kalitesini tahmin etmek için kullanılmaktadır (Payne et al 1987; Barro et al 
1997; Wieser \& Zimmermann 2000). Glu-A1, Glu-B1 ve Glu-D1 tarafindan kodlanan alleller farklı kalite özellikleriyle ilişkilidirler. Yüksek ekmek kalitesiyle ilişkili olan YMAG alt birimleri Glu-A1 tarafindan kodlanan 1 ve $2^{*}$, Glu-B1 tarafindan kodlanan $7+8,17+18,14+15$ ve $13+16$, Glu-D1 tarafindan kodlanan 5+10'dur (Guowang et al 2002; Tohver 2007). Yıldırım \& Çakmak yaptıkları çalışmada, yağmura dayalı (RF) ve sulu şartlar altında (IR) altı ekmeklik buğdayın (Sultan, Bezostaya, Süzen Harmankaya, Altay ve Gerek) diallel F4 melez döllerinde populasyon güçlerini değerlendirmişlerdir. $\mathrm{Bu}$ araştırma, ekmeklik buğdayın gen merkezlerinden birisi olan Türkiye'nin doğu bölgesi illerinden toplanan yerel ekmeklik buğday çeşitlerinden tane verimi ile bazı kalite özelliklerine göre seçilmiş 41 adet yerel ekmeklik buğday saf hattında [Erzurum ( 9 genotip), Kars (3 genotip), Van (13 genotip), Hakkari (5 genotip) ve Adryaman (11 genotip)] YMAG alt birimlerini belirlemek ve ekmeklik buğday kalite 1slahı açısından önemli bant/bant gruplarına sahip olup olmadıklarını saptamak amacıyla yapılmıştır.

\section{Materyal ve Yöntem}

Bu çalışmada materyal olarak; Erzurum (9 genotip), Kars (3 genotip), Van (13 genotip), Hakkari (5 genotip) ve Adıyaman (11 genotip) illerinden 32 yıllık periyotta (1962-1991) toplanan yerel ekmeklik buğday çeşitlerinden 2003-2005 yıllarında teksel (saf hat) seleksiyona göre seçilmiş 41 adet yerel ekmeklik buğday saf hattı kullanılmıştır. Saf hatların seçiminde tane verimi, protein oranı, bin tane ağırlığı, kuru gluten oranı, tane sertliği ve mini SDS sedimentasyon testi seleksiyon kriteri olarak kullanılmıştır (Akçura 2006). Materyalin çoğunluğunu Doğu Anadolu bölgemizin en önemli yerel buğday çeşitlerinden olan Erzurum ve Van illerimizde lavaş ekmek yapımına uygun olmasından dolayı tercih edilen Kırik (Bardsley \& Thomas 2005) ve Tir buğdayından seçilmiş saf hatlar oluşturmaktadır (Çizelge 1). YMAG proteinlerinin ekstraksiyonu ve Sodium Dodecyl Sulfate - Polyacrylamide Gel Electrophoresis (SDS-PAGE) analizi "Uluslararası Yeni Bitki
Çeşitlerini Koruma Birliği” (UPOV) ekmeklik buğday çeşit özellik belgesinde belirtilen yöntemin (UPOV 1994) çalışmaya uyarlanmış şekline göre yapılmıştır. Glutenin proteinlerinin ekstraksiyonu her bir genotipe ait bir başaktan alınan tek tohum tanesi kullanılarak yapılmıştır.

Tohum porselen havan içerisinde ezildikten sonra, ezilen kısımdan alınan $0.05 \mathrm{~g}$ un üzerine $1 \mathrm{M}$ Tris- $\mathrm{HCl}$ ( $\mathrm{pH}$ 6.8), \% 30 (weight/volume) Gliserol, \% 6 (weight/volume) sodyum dodesil sülfat (SDS) içeren ekstraksiyon çözeltisinden $1000 \mu \mathrm{L}$ ilave edilerek 2 saat oda sicaklığında inkübe edilmiş ve 12000 rpm'de 7 dakika santrifüj edilerek glutenin proteinleri elde edilmiştir. Elde edilen proteinlerin SDS-PAGE yöntemi kullanılarak YMAG alt birimleri belirlenmiştir. (UPOV 1994). Elektroforez işlemi $9 \mu \mathrm{L}$ glutenin proteini ile \% 3'lük yükleme jeli ve \% 14'lük ayırma jeli kullanılarak $60 \mathrm{~mA}$ ve $20^{\circ} \mathrm{C}$ 'de gerçekleştirilmiştir. Elektroforez işleminden sonra elde edilen jel yapıları bir gece Coomassie Brillant Blue- G250 ile boyandıktan sonra fotoğraflanarak değerlendirmeye alınmıştır. YMAG alt birimleri Payne et al (1984) 'in YMAG alt birimi numaralandırma sistemine göre tanımlanmıştır. Glutenin allelleri Gahazy et al (2012) ve MASWHEAT (2013) çalışmaları esas alınarak glutenin allel skor sistemine göre değerlendirilmiştir. YMAG bant desenlerinin belirlenmesinde standart genotip olarak Pavon (Glu A1 b, Glu B1 i, Glu D1 d), Opata (Glu A1 b, Glu B1 f, Glu D1 a), Trol (Glu A1 b, Glu B1 h, Glu D1 a), Gabo (Glu A1 b, Glu B1 i, Glu D1 a), Orca (Glu A1 b, Glu B1 a, Glu D1 a), Kadett (Glu A1 a, Glu B1 c, Glu D1 d ), Clement (Glu A1 c, Glu B1 d, Glu D1 a), Chinese Spring (Glu A1 c, Glu B1 b, Glu D1 a) kullanılmıştır.

\section{Bulgular ve Tartışma}

Çalışmada kullanılan yerel ekmeklik buğday saf hatlarının toplandığı lokasyonlar/pedigrileri, YMAG alt birimleri ve kalite skor değerleri Çizelge 1'de verilmiştir. YMAG bant desenlerinin belirlenmesinde standart çeşit olarak Pavon, Opata, Trol, Gabo, Orca, Kadett, Clement, Chinese Spring çeşitleri kullanılmıştır. Çalışmada saptanan 7 farklı 
Çizelge 1- Türkiye'nin doğu bölgesinden toplan yerel ekmeklik buğday çeşitlerinden seçilmiş 41 adet saf hattın yüiksek molekül ağırlıklı glutenin (YMAG) alt birimleri, toplandığı lokasyon/pedigree, ve kalite skor değerleri

Table 1-Locations/Pedigree and quality score and high molecular weight glutenin subunits (HMW-GS) for the 41 bread wheat pure lines selected from Eastern Turkey bread landraces

\begin{tabular}{|c|c|c|c|c|c|c|c|c|c|c|c|}
\hline \multirow[b]{2}{*}{ S.N. } & \multirow[b]{2}{*}{ Lokasyon / Pedigri } & \multicolumn{3}{|c|}{ Glu-Al } & \multicolumn{3}{|c|}{$G l u-B 1$} & \multicolumn{3}{|c|}{ Glu-Dl } & \multirow{2}{*}{$\begin{array}{c}\text { Toplam } \\
\text { kalite } \\
\text { skoru }\end{array}$} \\
\hline & & Allel & $\begin{array}{c}\text { Alt } \\
\text { birim }\end{array}$ & $\begin{array}{l}\text { Kalite } \\
\text { skoru }\end{array}$ & Allel & Alt birim & $\begin{array}{l}\text { Kalite } \\
\text { skoru }\end{array}$ & Allel & $\begin{array}{c}\text { Alt } \\
\text { birim }\end{array}$ & $\begin{array}{l}\text { Kalite } \\
\text { skoru }\end{array}$ & \\
\hline 1 & Adıyaman TR 49034/2 & $\mathrm{c}$ & $\mathrm{n}$ & 1 & b & $7+8$ & 3 & $\mathrm{a}$ & $2+12$ & 2 & 6 \\
\hline 2 & Adiyaman TR 50476/1 & $\mathrm{c}$ & $\mathrm{n}$ & 1 & $\mathrm{~b}$ & $7+8$ & 3 & $\mathrm{a}$ & $2+12$ & 2 & 6 \\
\hline 3 & Adiyaman TR 50465/6 & $\mathrm{c}$ & $\mathrm{n}$ & 1 & $\mathrm{~b}$ & $7+8$ & 3 & $\mathrm{a}$ & $2+12$ & 2 & 6 \\
\hline 4 & Adiyaman TR 49034/3 & $\mathrm{c}$ & $\mathrm{n}$ & 1 & $\mathrm{~b}$ & $7+8$ & 3 & $\mathrm{a}$ & $2+12$ & 2 & 6 \\
\hline 5 & Adiyaman TR 50465/1 & $\mathrm{c}$ & $\mathrm{n}$ & 1 & $\mathrm{~b}$ & $7+8$ & 3 & $\mathrm{a}$ & $2+12$ & 2 & 6 \\
\hline 6 & Adiyaman TR 49040/5 & c & $\mathrm{n}$ & 1 & b & $7+8$ & 3 & $\mathrm{a}$ & $2+12$ & 2 & 6 \\
\hline 7 & Adiyaman TR 49040/4 & c & $\mathrm{n}$ & 1 & $\mathrm{~b}$ & $7+8$ & 3 & $\mathrm{a}$ & $2+12$ & 2 & 6 \\
\hline 8 & Adiyaman TR 49040/6 & $\mathrm{c}$ & $\mathrm{n}$ & 1 & $\mathrm{~b}$ & $7+8$ & 3 & $\mathrm{a}$ & $2+12$ & 2 & 6 \\
\hline 9 & Adiyaman TR 50465/4 & c & $\mathrm{n}$ & 1 & b & $7+8$ & 3 & $\mathrm{a}$ & $2+12$ & 2 & 6 \\
\hline 10 & Adiyaman TR 46822/5 & $\mathrm{c}$ & $\mathrm{n}$ & 1 & $\mathrm{~b}$ & $7+8$ & 3 & $\mathrm{a}$ & $2+12$ & 2 & 6 \\
\hline 11 & Adiyaman TR 50476/5 & $\mathrm{c}$ & $\mathrm{n}$ & 1 & $\mathrm{~b}$ & $7+8$ & 3 & $\mathrm{a}$ & $2+12$ & 2 & 6 \\
\hline 12 & Erzurum TR 32790/1 & $\mathrm{c}$ & $\mathrm{n}$ & 1 & $\mathrm{~b}$ & $7+8$ & 3 & $\mathrm{a}$ & $2+12$ & 2 & 6 \\
\hline 13 & Erzurum TR 45370/5 & $\mathrm{c}$ & $\mathrm{n}$ & 1 & $\mathrm{~b}$ & $7+8$ & 3 & $\mathrm{a}$ & $2+12$ & 2 & 6 \\
\hline 14 & Erzurum TR 45370/6 & c & $\mathrm{n}$ & 1 & b & $7+8$ & 3 & $\mathrm{a}$ & $2+12$ & 2 & 6 \\
\hline 15 & Erzurum TR 32893/1 & $\mathrm{c}$ & $\mathrm{n}$ & 1 & $\mathrm{~b}$ & $7+8$ & 3 & $\mathrm{a}$ & $2+12$ & 2 & 6 \\
\hline 16 & Erzurum TR 45370/4 & $\mathrm{c}$ & $\mathrm{n}$ & 1 & b & $7+8$ & 3 & $\mathrm{a}$ & $2+12$ & 2 & 6 \\
\hline 17 & Erzurum TR 45370/6 & $\mathrm{c}$ & $\mathrm{n}$ & 1 & b & $7+8$ & 3 & $\mathrm{a}$ & $2+12$ & 2 & 6 \\
\hline 18 & Erzurum TR 32655/1 & $\mathrm{c}$ & $\mathrm{n}$ & 1 & b & $7+8$ & 3 & $\mathrm{a}$ & $2+12$ & 2 & 6 \\
\hline 19 & Erzurum TR 32780/3 & c & $\mathrm{n}$ & 1 & b & $7+8$ & 3 & $\mathrm{a}$ & $2+12$ & 2 & 6 \\
\hline 20 & Erzurum TR 32846/4 & $\mathrm{c}$ & $\mathrm{n}$ & 1 & b & $7+8$ & 3 & $\mathrm{a}$ & $2+12$ & 2 & 6 \\
\hline 21 & Hakkari TR 47981/1 & $\mathrm{c}$ & $\mathrm{n}$ & 1 & b & $7+8$ & 3 & $\mathrm{~d}$ & $5+10$ & 4 & 8 \\
\hline 22 & Hakkari TR 46763/1 & $\mathrm{c}$ & $\mathrm{n}$ & 1 & $\mathrm{~h}$ & $14+15$ & - & $\mathrm{d}$ & $5+10$ & 4 & $5+$ \\
\hline 23 & Hakkari TR 47982/5 & $\mathrm{c}$ & $\mathrm{n}$ & 1 & $\mathrm{~b}$ & $7+8$ & 3 & d & $5+10$ & 4 & 8 \\
\hline 24 & Hakkari TR 47981/4 & $\mathrm{c}$ & $\mathrm{n}$ & 1 & $\mathrm{~b}$ & $7+8$ & 3 & $\mathrm{~d}$ & $5+10$ & 4 & 8 \\
\hline 25 & Hakkari TR 47987/4 & c & $\mathrm{n}$ & 1 & b & $7+8$ & 3 & $\mathrm{a}$ & $2+12$ & 2 & 6 \\
\hline 26 & Kars TR 48025/6 & c & $\mathrm{n}$ & 1 & $\mathrm{~d}$ & $6+8$ & 1 & $\mathrm{a}$ & $2+12$ & 2 & 4 \\
\hline 27 & Kars TR 46851/1 & $\mathrm{c}$ & $\mathrm{n}$ & 1 & $\mathrm{~b}$ & $7+8$ & 3 & $\mathrm{a}$ & $2+12$ & 2 & 6 \\
\hline 28 & Kars TR 45904/6 & c & $\mathrm{n}$ & 1 & b & $7+8$ & 3 & $\mathrm{a}$ & $2+12$ & 2 & 6 \\
\hline 29 & Van TR 45410/4 & $\mathrm{c}$ & $\mathrm{n}$ & 1 & $\mathrm{~b}$ & $7+8$ & 3 & $\mathrm{a}$ & $2+12$ & 2 & 6 \\
\hline 30 & Van TR 45938/5 & $\mathrm{c}$ & $\mathrm{n}$ & 1 & $\mathrm{a}$ & 7 & 1 & $\mathrm{~d}$ & $5+10$ & 4 & 6 \\
\hline 31 & Van TR 45409/5 & $\mathrm{c}$ & $\mathrm{n}$ & 1 & $\mathrm{f}$ & $13+16$ & 3 & $\mathrm{~d}$ & $5+10$ & 4 & 8 \\
\hline 32 & Van TR 45410/5 & $\mathrm{c}$ & $\mathrm{n}$ & 1 & b & $7+8$ & 3 & $\mathrm{a}$ & $2+12$ & 2 & 6 \\
\hline 33 & Van TR 45402/4 & $\mathrm{c}$ & $\mathrm{n}$ & 1 & $\mathrm{f}$ & $13+16$ & 3 & $\mathrm{~d}$ & $5+10$ & 4 & 8 \\
\hline 34 & Van TR 32275/5 & $\mathrm{c}$ & $\mathrm{n}$ & 1 & b & $7+8$ & 3 & $\mathrm{a}$ & $2+12$ & 2 & 6 \\
\hline 35 & Van TR 47993/2 & $\mathrm{c}$ & $\mathrm{n}$ & 1 & $\mathrm{~b}$ & $7+8$ & 3 & $\mathrm{a}$ & $2+12$ & 2 & 6 \\
\hline 36 & Van TR 47995/3 & $\mathrm{c}$ & $\mathrm{n}$ & 1 & b & $7+8$ & 3 & $\mathrm{a}$ & $2+12$ & 2 & 6 \\
\hline 37 & Van TR 45399/2 & $\mathrm{c}$ & $\mathrm{n}$ & 1 & b & $7+8$ & 3 & $\mathrm{a}$ & $2+12$ & 2 & 6 \\
\hline 38 & Van TR 47995/5 & $\mathrm{c}$ & $\mathrm{n}$ & 1 & b & $7+8$ & 3 & $\mathrm{a}$ & $2+12$ & 2 & 6 \\
\hline 39 & Van TR 45402/1 & $\mathrm{c}$ & $\mathrm{n}$ & 1 & b & $7+8$ & 3 & $\mathrm{a}$ & $2+12$ & 2 & 6 \\
\hline 40 & Van TR 47995/4 & $\mathrm{c}$ & $\mathrm{n}$ & 1 & b & $7+8$ & 3 & $\mathrm{a}$ & $2+12$ & 2 & 6 \\
\hline 41 & Van TR 39676/4 & c & $\mathrm{n}$ & 1 & $\mathrm{i}$ & $17+18$ & 3 & $\mathrm{a}$ & $2+12$ & 2 & 6 \\
\hline
\end{tabular}


YMAG alt birimleri kombinasyonu arasinda en yaygin olan (\% 78.0) “n, 7+8, 2+12" kombinasyonu 32 saf hatta gözlenmiştir. $\mathrm{Bu}$ kombinasyonu sirasiyla 3 saf hatta $(\% 7.3)$ " $\mathrm{n}, 7+8,5+10$ ", 2 saf hatta $(\% 4.9)$ " $n, 13+16,5+10$ " ve 1 'er saf hatta $(\%$ 2.4) “n, 17+18, 2+12", "n, 6+8, 2+12", "n, 7, 5+10", ve "n, 14+15, 5+10" kombinasyonları izlemiştir. Doğu Anadolu Tarımsal Araştırma Enstitüsü Müdürlüğünce materyalin toplandığı bölgede yetiştirilmek üzere geliştirilen Lancer, Doğu-88, Karasu 90, Palandöken-97 gibi çeşitler YMAG alt ünitesi bakımından yerel çeşitlerden farklılık göstermektedir. Doğu- 88 çeşidinin; $2 * ; 7+9 ; 5+10$, Karasu 90 çeşidinin, 2*; 7+8; 5+10, Palandöken-97 çeşidinin, $1 ; 17+18 ; 5+10$ ve Lancer çeşidinin ise n; 7+8; 5+10 allel kombinasyonuna sahip olduğu bildirilmektedir (WHEAT PEDIGREE 2013). Doğu Anadolu bölgesi için geliştirilen çeşitlerden sadece Lancer çeşidinin allel kombinasyonları çalışma materyalinin allel kombinasyonuna benzemektedir.

YMAG alt birimlerini kullanarak buğdayın kaliteli ekmek olma potansiyelini değerlendirmek mümkün olmaktadır. Kalite skor değeri 9-10 olması yüksek kaliteyi, 8 olması genotipin ümitvar olduğunu ve 5 ve altında bir değer olması da düşük kaliteyi göstermektedir (Tabasum et al 2011). Ancak, buğdayda kalite kriterlerinin kullanım amacına göre değişebildiği göz ardı edilmemelidir (Stone \& Savin
1999). Çalışmada materyal olarak kullanılan 41 adet ekmeklik yerel ekmeklik buğday saf hattında kalite skoru 9 ve 10 olan hiçbir genotip belirlenememiştir. Sadece 5 genotip (\% 12.2) 8 kalite skoru ile değerlendirilmiş olup, 36 genotipin (\% 87.8) kalite skoru değeri ise 4-6 arasında değişmiştir. 41 adet ekmeklik yerel buğday genotipinin YMAG alt birimleri kombinasyonları Çizelge 2'de verilmişsir. Bununla birlikte bazı örneklerin ve standart genotiplerin elektroforetik bant desenleri Şekil 1'de verilmiştir.

Ekmek kalitesi ile arasında pozitif korelasyon olan YMAG alt birimlerinin; Glu-A1 lokusundan "1", "2*", Glu-B1 lokusundan "7+8", "17+18", "14+15"ve "13+16", Glu-D1 lokusundan " $5+10 "$ olduğu, düşük kaliteyi ifade eden alt birimlerin ise Glu-A1 lokusundan "n", Glu-B1 lokusundan "7", "6+8" ve " $20 "$, Glu-D1 lokusundan ise " $2+12 "$ olduğu farklı araştırıcılar tarafından ifade edilmiştir (Payne et al 1981; 1983; 1987; Ng \& Bushuk 1987; Lukow et al 1989). Tüm genotipler içerisinde Glu-A1 lokusuna ait sadece bir allel (GluA1c) belirlenmiştir. Sedimentasyon değeri, protein kalitesi, gluten kuvveti ve elastikiyet gibi kalite değerleri ile negatif ilişkili olan " $n$ " alleli çalışma materyalinin tamamı olan 41 (\% 100) genotipte belirlenmiş olup, pozitif ilişkili olan " 2 *" ve " 1 " allellerine ise hiçbir genotipte belirlenmemiştir. $\mathrm{Bu}$

Çizelge 2- Türkiye'nin doğu bölgesinden toplan yerel ekmeklik buğday çeşitlerinden seçilmiş 41 adet saf hattın yüksek molekül ağırlıklı glutenin (YMAG) alt birimleri kombinasyonları

Table 2- High molecular weight glutenin subunits (HMW-GS) combinations for the 41 bread wheat pure cultivars selected from Eastern Turkey bread landraces

\begin{tabular}{|c|c|c|c|c|c|c|}
\hline \multicolumn{4}{|c|}{$Y M A G$ alt birim kombinasyonu } & \multirow{2}{*}{ Adet } & \multirow{2}{*}{ Görülme sılklı̆gl (\%) } & \multirow{2}{*}{$\begin{array}{l}\text { Toplam kalite } \\
\text { skoru }\end{array}$} \\
\hline Glu-Al & Glu-B1 & Glu-D1 & Alleller & & & \\
\hline $\mathrm{n}$ & $17+18$ & $2+12$ & $\mathrm{c}, \mathrm{i}, \mathrm{a}$ & 1 & 2.4 & 6 \\
\hline $\mathrm{n}$ & $6+8$ & $2+12$ & $\mathrm{c}, \mathrm{d}, \mathrm{a}$ & 1 & 2.4 & 4 \\
\hline $\mathrm{n}$ & $7+8$ & $2+12$ & $\mathrm{c}, \mathrm{b}, \mathrm{a}$ & 32 & 78.0 & 6 \\
\hline $\mathrm{n}$ & 7 & $5+10$ & $\mathrm{c}, \mathrm{a}, \mathrm{d}$ & 1 & 2.4 & 6 \\
\hline $\mathrm{n}$ & $13+16$ & $5+10$ & $\mathrm{c}, \mathrm{f}, \mathrm{d}$ & 2 & 4.9 & 8 \\
\hline $\mathrm{n}$ & $14+15$ & $5+10$ & $\mathrm{c}, \mathrm{h}, \mathrm{d}$ & 1 & 2.4 & $5+$ \\
\hline $\mathrm{n}$ & $7+8$ & $5+10$ & $\mathrm{c}, \mathrm{b}, \mathrm{d}$ & 3 & 7.3 & 8 \\
\hline
\end{tabular}




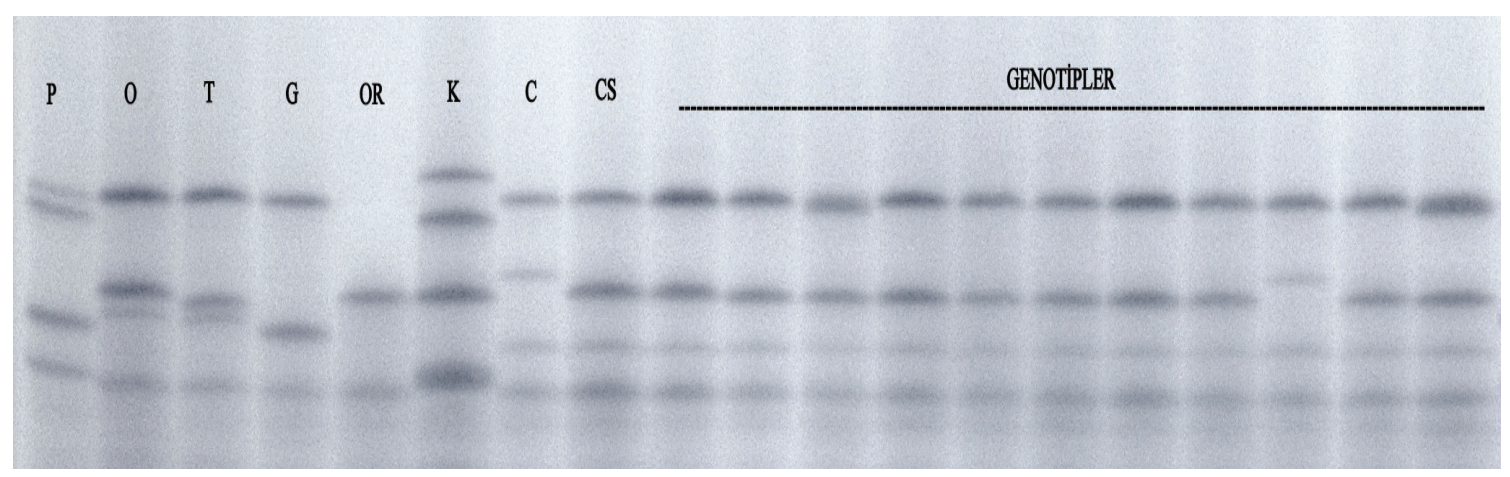

Şekil 1- Bazı yerel ekmeklik buğday çeşitlerinin ve standart çeşitlerin YMAG alt birim desenleri. Soldan sağa ilk sekiz sıra standart çeşitler; P, Pavon; O, Opata; T, Trol; G, Gabo; OR, Orca; K, Kadett; C, Clement; CS, Chinese Spring; son on bir sıra yerel ekmeklik buğday çeşitler

Figure 1- High molecular weight glutenin subunits (HMW-GS) of standard cultivars and 41 bread wheat genotypes selected from Turkish landraces. Left to right the first 8 (1-8) standard cultivars; P, Pavon; O, Opata; T, Trol; G, Gabo; OR, Orca; K, Kadett; C, Clement; CS, Chinese Spring, respectively; the last 11 (9-19) some Turkish landraces

durum; Erzurum, Kars ve Van illerinde olduğu gibi yerel buğdayların daha çok lavaş ekmek yapımında kullanmak üzere yetiştirilmesi ve materyal içerisinde de yer alan Kırik buğdayının bazı yörelerde bu özelliği yönünden özellikle tercih edilmesinin bir sonucudur (Bardsley \& Thomas 2005).

Materyal içinde belirlenen 9 adet Glu-1 allellinden 6 tanesi Glu-B1 lokusuna aittir. Bunlardan $7+8$ alt birimi \% 85.4'lük oranıyla 35 genotipte,
$13+16$ alt birimi $\% 4.9^{\prime}$ luk oranıla 2 genotipte, $7,14+15,17+18$ ve $6+8$ alt birimleri ise $\% 2.4$ 'lük oranıyla yalnızca 1 'er adet genotipte belirlenmiştir. Glu-D1 lokusunda ise 34 adet genotipin Glu-D1a $(2+12)$ alleline ve 7 genotipin de Glu-D1d $(5+10)$ alleline sahip olduğu saptanmıştır (Çizelge 3).

Çalışma materyalleri içerisinde Glu-A1 lokusuna ait sadece Glu-A1c (\% 100) alleli belirlenmiştir. Zhang et al (2002), Çin Halk Cumhuriyeti'nden

Çizelge 3- Türkiye'nin doğu bölgesinden toplan yerel ekmeklik buğday çeşitlerinden seçilmiş 41 adet saf hattın yüksek molekül ağırlıklı glutenin (YMAG) alt birimleri allelik varyasyonu

Table 3-Allelic variations of high molecular weight glutenin subunits (HMW-GS) for the 41 bread wheat pure cultivars selected from Eastern Turkey bread landraces

\begin{tabular}{ccccc}
\hline Lokus & Allel & Alt birim & Adet & Görülme siklı̆gl (\%) \\
\hline Glu-A1 & $\mathrm{c}$ & $\mathrm{n}$ & 41 & 100 \\
\hline \multirow{5}{*}{ Glu-B1 } & $\mathrm{a}$ & 7 & 1 & 2.4 \\
& $\mathrm{~b}$ & $7+8$ & 35 & 85.4 \\
& $\mathrm{~d}$ & $6+8$ & 1 & 2.4 \\
& $\mathrm{f}$ & $13+16$ & 2 & 4.9 \\
& $\mathrm{~h}$ & $14+15$ & 1 & 2.4 \\
Glu-D1 & $\mathrm{i}$ & $17+18$ & 1 & 2.4 \\
& $\mathrm{a}$ & $2+12$ & 34 & 82.9 \\
& $\mathrm{~d}$ & $5+10$ & 7 & 17.1 \\
\hline
\end{tabular}

Tarım Bilimleri Dergisi - Journal of Agricultural Sciences 21 (2015) 346-354 
toplamış oldukları 5129 yerel ekmeklik buğday genotipi üzerine yaptıkları çalışmada \% 91.2'lik oranda Glu-A1c alleli belirlemişlerdir. Rasheed et al (2012a) 95 adet sentetik hekzaploid buğday materyali ile yaptıkları çalışmada 68 adet genotipte (\% 71.6'lik) Glu-A1c alleli saptamışlardır. Hua et al (2005) tarafindan yine Çin Halk Cumhuriyeti Xinjiang lokasyonundan toplanmış 282 yerel buğday genotipi ile yapılan araştırmada \% 75.5 oran ile Glu A1c alleli belirlenmiştir. Rasheed et al (2012b)'1 F8 kademesinde bulanan 202 genotip üzerinde yaptıkları bir çalışmada, \% 63.87'lik oranda Glu-A1c alleli belirlemiş̧lerdir. $\mathrm{Bu}$ çalışmalarla çalışmamızın sonuçları büyük oranda benzerlik göstermektedir.

Çalışmada Glu-B1 lokusunda 6 adet allel belirlenmiş olup 35 adet genotip (\% 85.4) ile en çok görülen allel Glu-B1b olmuştur. Zhang et al (2002) ve Hua et al (2005)'da yaptıkları çalışmalarda benzer sonuçları elde ettiklerini rapor etmişlerdir. Rasheed et al (2012a) tarafindan 95 adet sentetik hekzaploid buğday ile yapılan bir çalışmada, genotiplerin $\%$ 43.2'sinde Glu-B1b alleli belirlemişlerdir. Fatehi et al (2008), 80 adet ekmeklik buğday genotipi kullanarak yaptıkları çalışmada materyallerinin $\% 45$ 'inde Glu-B1b alleli bulmuşlardır.

Yürütülen bu çalışmada ayrıca Glu-D1a alleline sahip 34 adet genotip ( $\%$ 82.9) belirlenmiştir. Nakamura \& Fujimaki (2002), Zhang et al (2002) ve Hua et al (2005) tarafindan yürütülen benzer çalışmalar ile bu çalışmanın uyumlu olduğu görülmüştür. $\mathrm{Bu}$ araştırmalarda Glu-D1a allelinin Glu-D1 lokusunun en yaygın görülen alleli olduğu bildirilmiş olup araştırma sonuçları bu yönüyle diğer çalışmalarla örtüşmüştür. Materyalin benzer özelliklere sahip olması öncelikle gen havuzlarının birbirlerine yakın coğrafik konumlarda olması veya gen havuzları çevresinde yaşayan insanların veya gen havuzu civarından geçen insanların göçleriyle yerel buğdayların bir gen merkezinden diğer bir gen merkezine ya da yetiştiricilik alanına aktarılması ile açıklanabilir. Diğer taraftan yüksek ekmek kalitesiyle Glu-D1d $(5+10)$ allelinin bulunmas1 arasında pozitif ilişkili bulunmaktadır (Payne et al 1981; 1983; 1987; Ng \& Bushuk 1987; Lukow et al
1989). Çalışma sonucunda sadece 7 adet genotipte (\% 17.0) Glu-D1d (5+10), 34 genotipte (\% 82.9) ise Glu-D1a $(2+12)$ allellerinin varlığ belirlenmiştir. Yerel buğday genotiplerinin glutenin ve gliadin bant desenleri ile ilgili ülkemizde sınırlı sayıda araştırmaya rastlanılmıştır. Demir et al (1998) tarafından yapılan bir araştırmada; ülkemizde yetiştiriciliğ i yapılmış olan bazı yerel buğdayların da bulunduğu 44 genotipte YMAG alt ünitesi bakımından farklılıklar araştırılmıştır. Bezostaja-1 çeşidinin $2^{*} ; 7+9 ; 5+10$, Flamura-85 çeşidinin $2 *$; $7+8 ; 5+10$, İkizce 96 çeşidinin $1 ; 7+8 ; 5+10$, Sünter genotipin de ise $2 * ; 7+8 ; 2+12$ YMAG allellerini taşıdığı bildirilmiştir.

Ekmek kalitesi ile arasında negatif korelasyon olan YMAG alt birimlerinin; Glu-A1 lokusundan "n", Glu-B1 lokusundan "7", " $6+8$ " ve " $20 "$, Glu-D1 lokusundan ise " $2+12$ " olduğu, yüksek ekmeklik kaliteyi niteleyen alt birimlerin ise Glu-A1 lokusundan "1", "2*", Glu-B1 lokusundan "7+8", "17+18", "14+15"ve "13+16", Glu-D1 lokusundan "5+10" olduğu farklı araştırıcılar tarafından ifade edilmişstir (Payne et al 1981; 1983; 1987; Ng \& Bushuk 1987; Lukow et al 1989; Weegels et al 1996). Bu bant ya da bantlara sahip genotipler buğday ıslahı programlarında kullanılacak materyallerdeki çeşitliliği artırabilecektir. Tüm materyal birlikte değerlendirildiğinde 41 genotipden sadece 5 genotipte ( $\%$ 12.2) kalite skoru 8 olarak değerlendirilmiştir. 36 genotip ise $(\%$ 87.8) kalite skoru 4-6 olarak değerlendirilirken hiçbir genotipin kalite skoru 9 ya da 10 olarak belirlenememiştir.

\section{Sonuçlar}

Türkiye'nin Doğu bölgesinin farklı illerinden toplanmış bazı yerel ekmeklik buğday çeşitlerinden tane verimi ve bazı kalite özelliklerine göre seçilmiş 41 saf ekmeklik buğday hattında SDS-PAGE yöntemi kullanılarak Glu-1 lokusunda bulunan YMAG bantlarının analizi yapılmıştır. 7 farklı YMAG alt birimleri kombinasyonu saptanan bu çalışmada en yaygın olarak görülen grup $32(\%$ 78.0) genotiple " $n, 7+8$ ve, $2+12$ " olmuştur. 5 genotip (\% 12.2) 8 kalite skoru ile değerlendirilmiş olup 36 genotipin (\% 87.8) skor değeri 4-6 kalite 
skoru ile değerlendirilmiştir. 8 kalite skoru ile değerlendirilmiş olan 21 (Hakkari TR 47981/1), 23 (Hakkari TR 47982/5), 24 (Hakkari TR 47981/4), 31 (Van TR 45409/5) ve 33 (Van TR 45402/4) numaralı yerel buğday hatları, ekmeklik buğday kalite sslahı çalışmalarında "genitör" olarak kullanılabilir. Türkiye'nin diğer üretim alanlarından toplanan yerel ekmeklik materyal içinde benzer veya aynı araştırma teknikleri kullanılarak kalite özelliklerinin belirlenmesi gerekmektedir.

\section{Teșekkür}

Bu çalışma; TÜBİTAK 1001 programı 1110255 numaralı araştırma projesi kapsamında yürütülmüsstür. Destek sağlayan TÜBİTAK'a teşekkür ederiz.

\section{Kaynaklar}

Akçura M (2006). Türkiye kışlık ekmeklik buğday genetik kaynaklarının karakterizasyonu. Doktora Tezi, Selçuk Üniversitesi Fen Bilimleri Enstitüsü (Basılmamış), Konya

Akçura M (2011). The relationships of some traits in Turkish winter bread wheat landraces. Turkish Journal of Agriculture and Forestry 35(2): 115-125

Bardsley D \& Thomas I (2005). Valuing local wheat landraces for agrobiodiversity conservation in Northeast Turkey. Agriculture, Ecosystems and Environment 106: 407-412

Barro F, Rooke L, Bekes F, Gras P, Tatham A S, Fido R, Lazzeri P, Shewry P R \& Barcelo P (1997). Transformation of wheat with HMW subunit genes results in improved functional properties. Nature Biotechnology 15(12): 1295-1299

Demir Z, Atlı A \& Baran I (1998). Glutenin subunit composition of some old and new wheat varieties in winter wheat growing regions of Turkey. Reports, $9^{\text {th }}$ International Wheat Genetics Symposium, University Extension Press, 2-7 August, Saskatoon, Canada, pp. 45-50

Fatehi F, Maleki M, Salavati A, Behamta M R, Zali A A \& Hoseinzadeh A H (2008). A determination of relationship between HMW glutenin subunits and bread making quality in bread wheat. Iranian Journal of Field Crop Science (Iranian Journal of Agricultural Sciences) 39(1): 43-52
Gahazy A I, Zanouny A, Moustafa K A \& Al-Doss A A (2012). Molecular screening of high molecular weight glutenin genes in spring bread wheat genotypes in Saudi Arabia. Journal of Food Agriculture Environment 10(1): 132-136

Guowang C, Feng X, Chuanxi M, Haobo W \& Zengliang Y (2002). Relation between HMW glutenin subunits and baking quality in bread wheat varieties. Journal of Anhui Agricultural College 29(4): 369-372

Hua C, Takata K, Yang-Fen Z, Ikeda T M, Yanaka M, Nagamine T \& Fujimaki H (2005). Novel high molecular weight glutenin subunits at the Glu-D1 locus in wheat landraces from the Xinjiang district of China and relationship with winter habit. Breeding Science 55(4): 459-463

Keçeli A (2008). Ekmeklik buğday'da (Triticum aestivum L.) kalite. Doktora Semineri, Ankara Üniversitesi Fen Bilimleri Enstitüsü (Basılmamış), Ankara

Lukow O M, Payne P I \& Tkachuk R (1989). The HMW glutenin subunit composition of Canadian wheat cultivars and their association with breadmaking quality. Journal of the Science of Food and Agriculture 46(4): 451-460

MASWHEAT (2013). Marker Assisted Selection in Wheat (MAS). http://maswheat.ucdavis.edu/ (Erişim tarihi: 13.08.2013)

Nakamura H \& Fujimaki H (2002). Specific Glu-D1f allele frequency of Japanese common wheat compared with distribution of Glu-1 alleles in Chinese wheat. Cereal Chemistry 79(4): 486-490

Ng P K W \& Bushuk W (1987). Glutenin of Marquis wheat as reference for estimating molecular weights of glutenin subunits by SDS-PAGE. Cereal Chemistry 64(4): 324-334

Payne P I \& Lawrence G J (1983). Catalogue or alleles for the complex gene loci, Glu-A1, Glu-B1 and Glu-D1 which code for the High-Molecular Weight subunit of glutenin whose in hexaploid wheat. Cereal Research Communication 11(1): 29-35

Payne P I, Holt L M \& Law C N (1981). Structural and genetical studies on the high-molecular-weight subunits of wheat glutenin. Part I. Allelic variation in subunits among varieties of wheat (Triticum aestivum L.). Theoretical and Applied Genetics 60(4): 229-236

Payne P I, Holt L M, Jackson E A, Law C N (1984). Wheat storage proteins: Their genetics and their potential for manipulation by plant breeding. Philosophical 
Transactions of the Royal Society London 304(1120): 359-371

Payne P I, Nightingale M A, Krattiger A F \& Holt L M (1987). The relationship between HMW glutenin subunit composition and the bread-making quality of British-grown wheat varieties. Journal of the Science of Food and Agriculture 40(1): 51-56

Rasheed A, Safdar T, Gul-Kazi A, Mahmood, Akram Z \& Mujeeb-Kazi A (2012a). Characterization of HMW-GS and evaluation of their diversity in morphologically elite synthetic hexaploid wheats. Breeding Science 62(2): 365-370

Rasheed A, Mahmood T, Gul Kazi A, Ghafoor A \& Mujeeb-Kazi A (2012b). Allelic variation and composition of HMW-GS in advanced lines derived from D-genome synthetic hexaploid/bread wheat (Triticum aestivum L.). Journal of Crop Science and Biotechnology 15(1): 1-7

Rogers W J, Payne P I \& Harinder K (1989). The HMW glutenin subunit and gliadin compositions of GermanGrown wheat varieties and their relationship with bread-making quality. Plant Breeding 103(2): 89-100

Shewry P, Napier J A \& Tatham A S (1995). Seed storage proteins: Structures and biosynthesis. The Plant Cell 7(7): 845-956

Stone J P \& Savin R (1999). Grain quality and its physiological determinants, wheat ecology and physiology of yield determination. E H Stone \& G A Slafer (Eds), Food Product Press, New York, pp. 95-115

Tabasum A, Iqbal N, Hameed A \& Arshad R (2011). Evaluation of Pakistani wheat germplasm for bread quality based on allelic variation in HMV glutenin subunits. Pakistan Journal of Botany 43(3): 17351740

Tohver M (2007). High molecular weight (HMW) glutenin subunit composition of some Nordic and Middle European wheats. Genetic Resource Crop Evolution 54(1): 67-81

TÜİK (2013). Tarım istatistikleri. www.tuik.gov.tr (Erişim tarihi: 13.08.2013)

UPOV (1994). The international union for the protection of new varieties of plants. Guidelines for the conduct of tests for distinctness, uniformity and stability for wheat No. TG/3/11, pp. 36, www.upov.int. (Erişim Tarihi: 14.02.2012)

Weegels P L, Hamer R J \& Schofield J D (1996). Functional properties of wheat glutenin. Journal of Cereal Science 23(1):1-18

WHEAT PEDIGREE (2013). Genetic resources information system for wheat and triticale. www. wheatpedigree.net (Erişim tarihi: 16.08.2013)

Wieser H \& Zimmermann G (2000). Importance of amounts and proportions of high molecular weight subunits of glutenin for wheat quality. European Food Research and Technology 210(5): 324-330

Yildırım M \& Çakmak M (2014). The Population Vigors of Diallel F4 Offsprings of six bread wheat genotypes for grain yield under irrigated and rain-fed conditions. Tarım Bilimleri Dergisi - Journal of Agricultural Sciences 20(4): 446-453

Zhang X U, Pang B S, You G X, Wang L F, Jia J Z \& Dong Y C (2002). Allelic variation and genetic diversity at Glu-D1 loci in Chinese wheat (Triticum aestivum L.) germplasm. Agricultural Sciences in China 1(10): 1074-1082 